\title{
Prevalence and knowledge of hypertension among people living in rural communities in Ghana: a mixed method study
}

\author{
Peter Agyei-Baffour ${ }^{1}$, Georgiette Tetteh², Dan Yedu Quansah³, Daniel Boateng ${ }^{1}$
}

1. School of Public Health, Kwame Nkrumah University of Science and Technology, Kumasi, Ghana.

2. Shai Osu-Doku District Hospital, Ghana Health Service, Accra, Ghana.

3. Service of Endocrinology, Diabetes \& Metabolism, Lausanne University Hospital, Lausanne, Switzerland

\section{Author details:}

1. Peter Agyei-Baffour: Email: agyeibaffourp@gmail.com

2. Georgiette Tetteh: Email: geobaf13@gmail.com

3. Dan Yedu Quansah: Email: dan_quansah@yahoo.com

4.Daniel Boateng: Email: kingdannie@gmail.com

\begin{abstract}
Background: Knowledge and understanding of hypertension and its associated health risks remain inadequate despite increasing trend of hypertension prevalence. This study was conducted to assess the prevalence, knowledge and perceptions of hypertension in rural communities in Ghana.

Methods: A mixed method study involving 534 subjects was employed. Data was collected in six communities from May to December 2014 with structured questionnaires and interview guides. A logistic regression analysis was conducted to estimate the influence of the socio-demographic factors on knowledge of hypertension. Qualitative data was thematically analyzed.

Results: The mean systolic blood pressure (BP) was higher in men than women (127.42 $\mathrm{mmHg}$ versus $124.42 \mathrm{mmHg})$. The proportion of hypertensives was $21.4 \%$ and was higher among men in all age categories. Knowledge on some risk factors of hypertension was extremely low. Having formal education was associated with higher odds of knowledge of hypertension (Adjusted odds ratio $[\mathrm{AOR}]$; $95 \%$ confidence interval $[\mathrm{CH}]=2.28 ; 1.25-4.16)$. Several misconceptions such as the use of agro-chemicals, fertilizers and excess vitamins were identified as causes of hypertension.

Conclusion: This study demonstrates an increased prevalence of hypertension, knowledge gaps and misconceptions surrounding hypertension in rural communities in Ghana. This evidence is useful in streamlining interventional programmes aimed at improving knowledge and prevention of hypertension.
\end{abstract}

Keywords: Hypertension, knowledge, prevalence, rural communities, Ghana, blood pressure.

DOI: https://dx.doi.org/10.4314/ahs.v18i4.12

Cite as: Agyei-Baffour P, Tetteh G, Quansah DY, Boateng D. Prevalence and knowledge of hypertension among people living in rural communities in Ghana: a mixed method study. Afri Health Sci. 2018;18(4): 931-941. https:// dx.doi.org/10.4314/abs.v18i4.12

\section{Corresponding author: \\ Daniel Boateng, School of Public Health, Kwame Nkrumah University of Science and Technology, Kumasi, Ghana. \\ Email: kingdannie@gmail.com}

\section{Introduction}

Hypertension remains a major public health challenge and it is identified as the leading risk factor for cardiovascular morbidity and mortality ${ }^{1-3}$. It accounts for one-third of the global preventable premature deaths annually ${ }^{4,5}$. In 2006, hypertension was documented as the primary cause of death in over 56,000 deaths and as a contributing factor in an additional 250,000 deaths out of the

(C) 2018 Agyei-Baffour et al. Licensee African Health Sciences. This is an Open Access article distributed under the terms of the Creative commons Attribution License (https://creativecommons.org/licenses/BY/4.0), which permits unrestricted use, distribution, and reproduction in any medium, provided the original work is properly cited. 
2.4 million deaths in the United States alone $e^{6}$ There is an estimated increase in the prevalence of hypertension by $17 \%$ in the next decade, with the greatest increase in the African region if effective preventive measures are not implemented ${ }^{7}$, making it a major health problem in developing countries ${ }^{8,9}$.

In Ghana, hypertension is the second leading cause of outpatient morbidity in adults older than 45 years, and trends in hypertension prevalence and incidence continue to grow $^{10}$. The prevalence of hypertension in rural and urban Ghana ranges from $19 \%$ to $48 \%{ }^{11}$ and some studies from rural settings reported $24 \%$ or higher ${ }^{12-15}$. In the Asutifi South district of Ghana, hypertension is consistently ranked among the top ten Out-Patient Department (OPD) cases with prevalence rising from $4.23 \%$ in 2008 to $6.07 \%$ in $2012^{16}$. Factors which drive this wave in the sub-region, including but not limited to changes in dietary patterns and sedentary lifestyles, ${ }^{17}$ could be prevented if knowledge of these factors are high among the general populace.

Knowledge gaps are important barriers in the effective prevention and treatment of hypertension ${ }^{18,19}$. In the advent of scarce resources to improve management and control of hypertension, there is the need to focus attention on preventive measures, which target behavioural change through education and awareness creation. Several models have proposed knowledge as important for health behaviours and sustained behavioural changes ${ }^{20-22}$. Although these models may differ in content and perspective, they stress the importance of evaluating the perceptions, attitudes, beliefs, and outcome expectations of individuals as crucial means to understand observed behaviours and to guide behavioural change. Knowledge of a disease condition influences patient's attitude and practice, and improves compliance with treatment and subsequent reduction in prevalence ${ }^{23}$.

Patients' knowledge and understanding of the potential health risks associated with hypertension, and the potential positive effects of lifestyle modification are inadequate $^{24,25}$. A study by Rizwana et $\mathrm{al}^{26}$ reported a huge gap in knowledge of modifiable risk factors of hypertension. A study in a sub-urban Nigerian community ${ }^{27}$ also showed low levels of knowledge of hypertension, with only $18 \%$ of respondents having knowledge of risk fac- tors of hypertension. Other studies from the sub region have shown similar results ${ }^{28}$.

Factors such as lack of formal school education, communication gaps, and inaccessibility to routine health education programme have been noted to hamper the knowledge of hypertension, especially among rural and minority populations ${ }^{29}$. Despite the growing evidence of increasing burden of hypertension and other risk factors of cardiovascular diseases (CVDs) in Ghana and similar parts in the sub-Saharan region, there is little evidence of in-depth understanding and knowledge, perceptions and practices of hypertension especially in rural areas. Majority of the previously conducted studies used only quantitative methods to explore knowledge level and perception of hypertension, with little in-depth exploration of patients' views, understanding and perception of hypertension. Documenting the depth of knowledge of hypertension among this population is necessary to successfully guide health promotion programmes. This study employed a mixed methods approach to provide converging evidence on the level of knowledge and prevalence of hypertension in rural Ghana.

\section{Materials and methods Study setting}

This was a cross-sectional study, which employed both qualitative and quantitative methods. The inclusion of a qualitative method helped to assess the in-depth understanding of knowledge and perceptions, which will be difficult to elucidate with quantitative tools, and by so doing provide much stronger evidence.

The study was conducted in the Asutifi South District in the Brong Ahafo Region of Ghana. The district has an estimated population of 53,584 with men and women constituting 28,285 (53\%) and 25,299 (47\%) respective$1 \mathrm{y}^{30}$. The major economic activity in the district is peasant farming. It is one of the known food baskets and also contributes a large proportion of cocoa and other tree crop production in Ghana.

\section{Study population and sample}

The study population were farmers aged 25 years and above. The inclusion criteria were; having lived in the community for not less than six months and voluntarily consenting to participate in the study. Participants who 
had resided in the community for less than six months were excluded. Two out of four sub-districts; Hwidiem and Nkaseim sub-districts were selected for the study. Six communities were selected; three from each sub-district. These were Amanfrom, Atta-ne-Atta and Woromso from Hwidiem sub-district and Apenimadi, Ohiatua, and Mmosiaso from Nkaseim sub-district. In the selected communities, the required respondents were selected first by clustering the communities into four, using the four cardinal points. Households were then selected using a sampling interval of 1:4. In the selected households, respondents were sampled using the lottery method where pieces of papers with inscriptions "Yes" and "No" were written for picking. Respondents who picked "Yes" and consented to participate in the study were enrolled. A total of 506 and 28 subjects were involved in the quantitative and qualitative data collection respectively.

\section{Data collection and statistical analysis Qualitative study}

Focus group discussions (FGDs) involving two (2) groups of six participants of same gender and two groups of eight, comprising of both men and women. Interviews and discussions were conducted and audio-taped in the local language, translated to English and then transcribed. Interviews were carried out in quiet and discreet locations in the communities, using a digital voice recorder. Coherency and grammatical errors in the transcripts were edited and coded for analysis. Data was coded with the help of NVIVO software for qualitative research ${ }^{31}$ and analyzed thematically. The codes were stored within nodes in the software. We further identified duplications in the codes and then explored possible connections between various themes, with the use of electronic memos in the software. The various themes identified were grouped under the knowledge of causes, prevention and sources of information on hypertension.

\section{Quantitative study}

Data was collected using structured questionnaires with open-ended and closed questions. These were used to obtain information on socio-demographic characteristics (age, sex, education level, occupation, marital status and religion) and knowledge, sources of information, risk factors and prevention of risk factors of hypertension. Blood pressure was measured at a seated position using sphygmomanometer and a stethoscope. Three different measurements were taken and the average used. Hypertension was defined as having systolic/diastolic blood pressures of $>$ or $=140 / 90 \mathrm{~mm} \mathrm{Hg}$.

The outcome variable was awareness of hypertension and the explanatory variables were socio-demographic characteristics (age, gender, education, relationship status and religion). Data were analyzed by descriptive and inferential statistics using STATA 11 software $^{32}$. Bivariate associations were tested using Pearson chi-square. A logistic regression analysis was conducted to estimate the association between the socio-demographic factors and knowledge of hypertension. All statistical analyses were significant at 95\% confidence level.

\section{Results \\ Background characteristics}

The mean age (standard deviation, SD) of the respondents was 39 years (14.5) and almost half were aged between 25 and 34 years. Majority, 58.4\% were women and almost 50\% had basic education. Only 1.6\% had tertiary education and $39 \%$ had no formal education. Most of the respondents were employed. $74.4 \%$ of respondents were married, $15.5 \%$ were single and $4.8 \%$ and $5 \%$ were divorced and widowed respectively. About $82 \%$ were Christians. Among participants for the FGDs, 56\% had basic education while $33 \%$ had no formal education.

\section{Prevalence of hypertension}

The mean diastolic (SD) and systolic pressures (SD) were $81.52 \mathrm{mmHg}(63.38)$ and $126.57 \mathrm{mmHg}$ (20.16) respectively. The mean systolic pressure was higher among men compared to women $(127.42 \mathrm{mmHg}$ versus 124.42 $\mathrm{mmHg}$ ) and it increased with increasing age in men and women, Fig 1. About $20.2 \%$ had systolic pressures above $140 \mathrm{mmHg}$ and the proportion of hypertensives was $21.4 \%$. The proportion of hypertensive increased with increasing age in both sexes and it was higher among male respondents in all age categories, with the exception of those older than 59 years, Fig 2. 

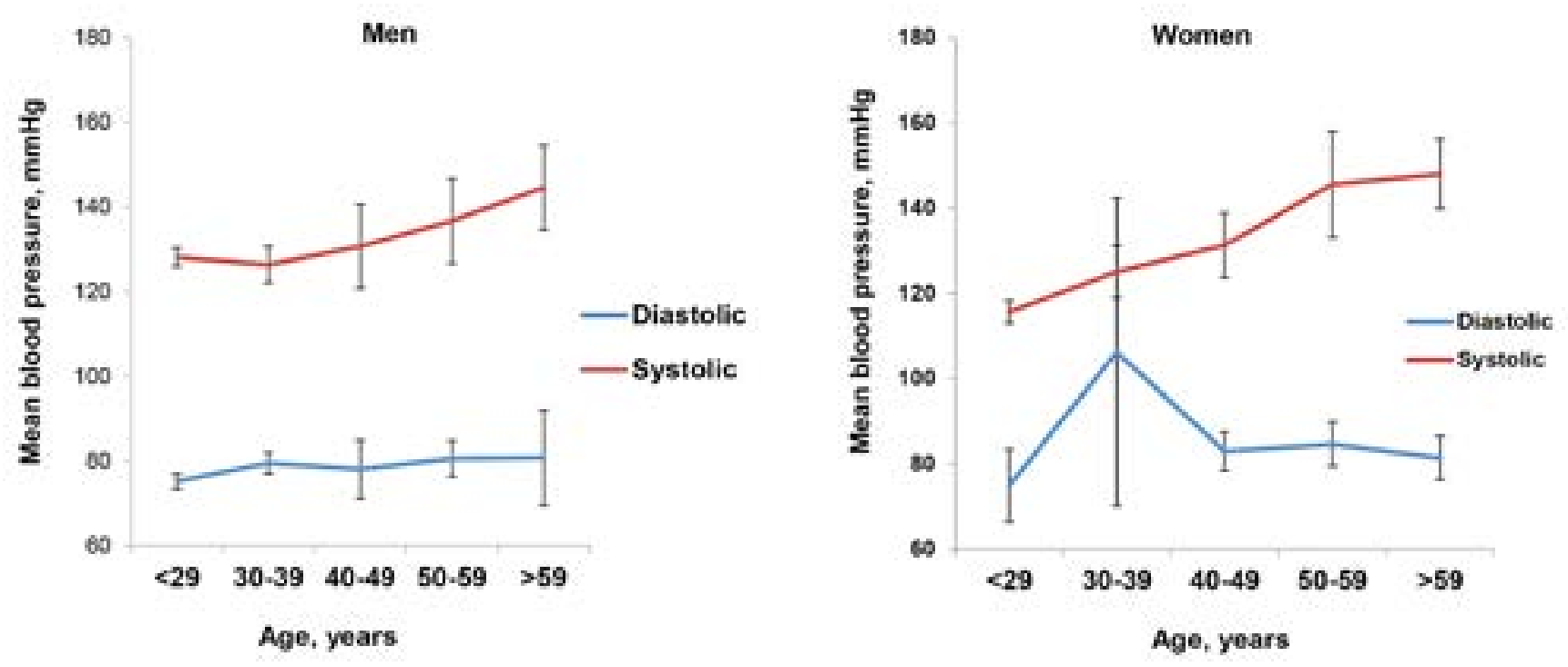

Fig 2 Proportion of hypertension by gender

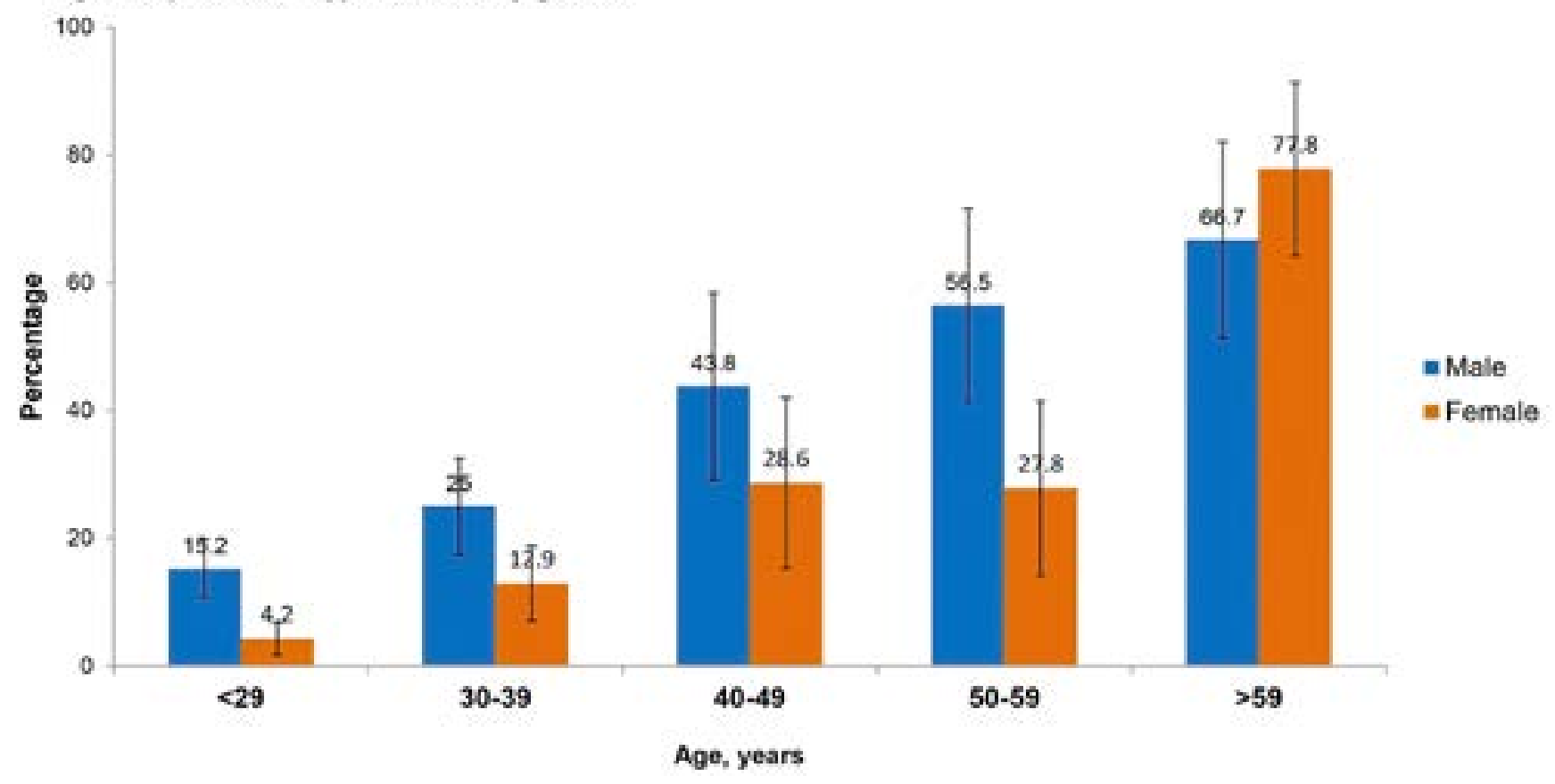

\section{Knowledge about Hypertension}

Table 1 presents respondents' awareness and knowledge of causes, symptoms and prevention of hypertension. Majority $(87.2 \%)$ had heard about hypertension and about $79 \%$ believed poor diet could cause hypertension. Knowledge on the influence of inactivity and weight gain on hypertension was extremely low $(11 \%$ and $3 \%$ respectively).
Respondents' knowledge on the importance of physical exercise and stress reduction in the prevention of hypertension was equally very low $(4.3 \%$ and $2.7 \%$ respectively). More than $50 \%$ agreed to palpitation as a symptom of hypertension whereas $26.5 \%$ indicated dizziness. More than $90 \%$ visited the health facility when their BP was high. On the other hand, 3.9\% and 1.2\% visited the herbalist and prayer camp respectively. The most cited source of information about hypertension was the media $(57.3 \%)$, followed by health staff $(32.7 \%)$. 
Table 1 Knowledge and sources of information on hypertension

\begin{tabular}{|c|c|c|}
\hline Variables & Frequency & Percentage \\
\hline \multicolumn{3}{|l|}{ Heard about blood pressure $(n=492)$} \\
\hline - Yes & 429 & 87.2 \\
\hline$-\quad$ No & 63 & 12.8 \\
\hline \multicolumn{3}{|l|}{ Causes of high blood pressure $(n=462)$} \\
\hline - Dieting & 365 & 79.0 \\
\hline - Inactivity & 51 & 11.0 \\
\hline - Weight gain & 14 & 3.0 \\
\hline - Genetics & 13 & 2.8 \\
\hline - Drugs related & 19 & 4.2 \\
\hline \multicolumn{3}{|l|}{ Prevention of hypertension $(n=484)$} \\
\hline - Exercise & 21 & 4.3 \\
\hline - Checking diet & 350 & 72.3 \\
\hline - Check BP regularly & 67 & 13.8 \\
\hline - Taking enough rest & 13 & 2.7 \\
\hline - Reducing stress & 12 & 2.7 \\
\hline - Other & 20 & 4.1 \\
\hline \multicolumn{3}{|l|}{ Symptoms of high BP $(n=480)$} \\
\hline - Dizziness & 127 & 26.5 \\
\hline - Palpitation & 272 & 56.7 \\
\hline - Fatigue & 81 & 16.8 \\
\hline \multicolumn{3}{|c|}{ Been told by health staff $B P$ is high $(n=480)$} \\
\hline - Yes & 70 & 14.6 \\
\hline$-\quad$ No & 410 & 85.4 \\
\hline \multicolumn{3}{|c|}{ First action after being told of hypertension $(n=145)$} \\
\hline - Nothing & & \\
\hline - Visited health facility & 74 & 51.0 \\
\hline - Visited herbalist & 64 & 44.1 \\
\hline - Went to see pastor & 5 & 3.5 \\
\hline - Bought drugs from chemist & 1 & 0.7 \\
\hline & 1 & 0.7 \\
\hline \multicolumn{3}{|c|}{ Place people seek care when BP is high $(n=491)$} \\
\hline - Health facility & 465 & 94.7 \\
\hline - Herbalist & 19 & 3.9 \\
\hline - Prayer camp & 6 & 1.2 \\
\hline - Chemist & 1 & 0.2 \\
\hline \multicolumn{3}{|l|}{ Where usually seek care $(n=491)$} \\
\hline - Health facility & 464 & 94.5 \\
\hline - Herbalist & 16 & 3.3 \\
\hline - Prayer camp & 1 & 0.2 \\
\hline - Chemist & 10 & 2.0 \\
\hline \multicolumn{3}{|c|}{ How often visit source of healthcare $(n=486)$} \\
\hline - Once a while & 243 & 50.0 \\
\hline - Very often & 73 & 15.0 \\
\hline - Often & 31 & 6.4 \\
\hline - Rare & 139 & 28.6 \\
\hline \multicolumn{3}{|c|}{ Sources of information on hypertension $(n=452)$} \\
\hline - Media & 259 & 57.3 \\
\hline - Health staff & 148 & 32.7 \\
\hline - Friends & 28 & 6.2 \\
\hline - Herbalist & 12 & 2.7 \\
\hline - Church or mosque & 5 & 1.1 \\
\hline
\end{tabular}

The level of awareness did not differ much by hypertension status. Awareness of hypertension was almost equal between hypertensives and non-hypertensives in men $(84.6 \%$ versus $85.8 \%)$ and was slightly higher in hypertensives than non-hypertensives in women $(91.8 \%$ versus $86.8 \%$ ). The level of awareness however differed significantly by the level of education, with awareness being higher among respondents with formal education
(90.6\% versus $81.5 \%)$, Table 2 . The adjusted odds ratios (AOR) shows higher odds of being aware of hypertension among those with formal education compared to those with no formal education (AOR; 95\%CI=2.28; 1.25-4.16). The level of awareness was also significantly lower among those divorced or widowed, compared to those who were married or cohabiting. The significance was however attenuated in the adjusted model, Table 2. 


\begin{tabular}{|c|c|c|c|c|}
\hline Variables & $\mathbf{N}(\%)$ & $\begin{array}{c}\% \% \\
\text { Awareness }\end{array}$ & OR $[95 \% C I]$ & AOR $[95 \% C I]$ \\
\hline \multicolumn{5}{|l|}{ Age } \\
\hline$-\quad<35$ & $249(49.2)$ & 88.3 & 1.00 & 1.00 \\
\hline$-\quad 36-45$ & $129(25.5)$ & 83.9 & $0.69[0.37,1.28]$ & $0.74[0.38,1.42]$ \\
\hline$-\quad 46-55$ & $46(9.1)$ & 95.7 & $2.91[0.67,12.65]$ & $3.12[0.67,14.53]$ \\
\hline - $56-65$ & $42(8.3)$ & 88.1 & $0.98[0.36,2.69]$ & $1.04[0.35,3.11]$ \\
\hline$-\quad>65$ & $40(7.9)$ & 79.5 & $0.51[0.21,1.22]$ & $0.80[0.28,2.29]$ \\
\hline \multicolumn{5}{|l|}{ Gender } \\
\hline - Male & $203(41.6)$ & 85.5 & 1.00 & 1.00 \\
\hline - Female & $285(58.4)$ & 87.7 & $1.21[0.71,2.06]$ & $1.54[0.84,2.85]$ \\
\hline \multicolumn{5}{|l|}{ Education } \\
\hline - No formal & $196(39.0)$ & 81.5 & 1.00 & 1.00 \\
\hline - Formal & $306(61.0)$ & 90.6 & $2.20[1.29,3.76]^{* *}$ & $2.28[1.25,4.16]^{* *}$ \\
\hline \multicolumn{5}{|l|}{ Religion } \\
\hline - Muslim/other & $91(18.0)$ & 86.8 & 1.00 & 1.00 \\
\hline - Christian & $415(82.0)$ & 89.2 & $0.80[0.38,1.69]$ & $0.73[0.33,1.60]$ \\
\hline \multicolumn{5}{|l|}{ Marital status } \\
\hline - Married/cohabiting & $376(74.7)$ & 89.3 & 1.00 & 1.00 \\
\hline - Single & $78(15.5)$ & 81.8 & $0.54[0.28,1.04]$ & $0.59[0.29,1.23]$ \\
\hline - Divorced/widowed & $49(9.8)$ & 79.6 & $0.47[0.22,1.00]^{*}$ & $0.48[0.19,1.23]$ \\
\hline
\end{tabular}

${ }^{*} P<0.05 ;{ }^{*} p<0.01 \quad$ OR=Odds Ratio AOR=Adjusted Odds Ratio

\section{Results from qualitative sub-study \\ Causes of hypertension}

In the qualitative sub-study, some respondents understood the causes of hypertension as related to diet and lack of exercise. They explained that:

'The foods that we eat and the time that we eat cause high blood pressure. Foods like fatty meats cause blockages of the blood vessels so that the heart is not able to pump blood to the body and it causes problems like hypertension' (male group, 58 years).

'[...] Again our diet; late night eating. Someone will pound 'fufu' in the evening and eat and sleep immediately after eating without any exercise. All these do not help but bring problems like high blood pressure' (Female, mixed group, 41 years).

Agro-chemical and fertilizer cause hypertension: misconceptions on causes of hypertension

The use of agro-chemicals in farming and eating certain kinds of foods were some of the major misconceptions presented by respondents as causes of hypertension throughout the discussions. Some participants explained that:

'[...] We have learnt some things from the white man where we use some chemicals for crop production. The white man protects himself when using such chemicals but when we are using it we don't protect ourselves so the hairs on the skin have small pores where these chemicals pass into our bodies and bring about high BP' (male group, 55years)

'[...] Everything is fertilizer now and ammonia and these chemicals are poisonous to us. Now that we eat we don't see but after two to three years it begins to manifest and by age 40 to 50 years you've developed high blood pressure' (male group, 47 years).

"[...] When you eat unhygienic foods you get high BP but when you eat hygienic foods, you will not get high BP" (female group, 35 years).

'What causes the condition (BP) is the 'Kontomire' (palava source) that we eat. The excess vitamins that we consume; if we consume more of it every day then we can develop high blood pressure' (mixed group, female, 59 years). 
Other related misconceptions included drinking water from old fridges and blood being in excess in the body. Some participants disclosed;

'[...] It is believed that old refrigerators can cause high blood pressure due to variation in temperature. When we put water into a fridge and it freezes and it is not drank while cold but put down to get hot and put back for refreezing before drinking, it could cause bigh blood pressure' (FGD, male group).

"[...] I know high BP is when your blood is in excess and you go to the hospital you are able to donate blood to other people who are in need of blood' (male, mixed group, FGD).

A male participant from the mixed group even believed gonorrhea causes hypertension:

"[...] ... a lot! They say gonorrhea can also cause bypertension" (male, 57 years).

\section{Knowledge on prevention of hypertension}

The importance of diet and exercise on the risk of hypertension was universal knowledge among the respondents. Some respondents were also of the opinion that adhering to health professionals' advice could help prevent hypertension. Some participants disclosed;

'They say when we watch our diet well we can protect ourselves from getting high BP. Again, if we exercise regularly, then we can protect ourselves from high $B P^{\prime}$ (female, mixed group, 37 years).

'[...] We should sleep early; we should not eat fresh and fatty meat. We should eat more smoked fish like 'nsesaawa' (smoked herrings)' (female, mixed group, 29 years).

'Taking proper care of yourself like your diet or every morning you engage in exercise like jogging and also avoiding alcohol consumption and excessive thinking will help you protect yourself from high blood pressure' (male group, 40years).

In relation to the stated causes, some respondents believed that avoiding contact with agro-chemicals and minimizing the use of fertilizer in agriculture could helpprevent hypertension.

Further on importance of exercise in preventing hypertension, almost all participants in the FGDs were of the view that their farm work was inadequate to exercise their body in order to prevent non-communicable diseases like hypertension. Participants suggested other forms of exercise. A participant said;

'Jogging, running and playing soccer is good to stay bealthy and prevent the condition' (female group, 36years).

\section{Detection of hypertension}

Most participants disclosed that one could know he/she is hypertensive when he/she feels numbness in the hands and feet, the heart beats faster and easily gets tired when walking. Some participants noted:

'[...] The hands usually becomes numb and the legs or the entire body becomes numb and when you touch something you are not able to grasp it properly. This is because the blood are not able to flow freely in the blood vessels because are blocked (mixed group, male, 61 years).

'If a person get high blood pressure, his heart beats faster. He misses a heartbeat upon hearing a message and he easily gets tired upon walking few distance' (female group, 54 years).

Other participants were however of the view that hypertension is not easily detectable unless one visits the facility and he/she is examined by health workers, who can tell whether one is hypertensive or not.

'Sometimes you cannot tell the changes in your body by yourself unless you go to the hospital where the doctors will check your blood pressure and confirm high blood pressure' (male group, 39years). 'When you go to the hospital and you are checked with a machine, it will tell whether you have high blood pressure or not' (male group 32 years).

\section{Sources of health information about hypertension}

The health worker was a major source of information on hypertension. A male respondent from the mixed group explained:

"I think how we manage to hear is from the doctors (health workers). Say, when we are sick, the directions and instructions that they tell us to follow. [.....] We follow their explanation it helps us to know what you will do to get blood pressure" (59 years).

"Most of the information is normally taken from physicians. They often tell us "do not eat this, do not do this" and we take cues from that' (Male group, 38 years).

On the other hand, some participants got information on hypertension from herbal medicine sellers and from the electronic media. They disclosed;

'[...] Like my brother said, at times those herbal medicine sellers at the information center are the ones who make us know about such diseases so they help us get information on the air waves concerning how to protect ourselves' (male group, 53 years).

'I also heard it in the news on radio and TV discussion when they make an advertisement or a campaign about it that it [...]' (male, mixed group, 59 years).

A follow up question on source of health care when one is hypertensive revealed that most of the respondents prefer the health facility as a general source of health care and also when they feel or are diagnosed of hyperten- 
sion. Some participants however believed in herbal medications.

'[...] The bible teaches us to use the herbs of the plant for medicine. Our old woman at home has herbal medications for high BP which are very good so I think I like herbal treatment' (male, mixed group, 61 years).

\section{Discussion}

\section{Prevalence of Hypertension}

This study revealed a high prevalence of hypertension in the district. About $21 \%$ of the farmers were found to be hypertensive. This somewhat parallels the crude prevalence of hypertension reported in many previous studies. This included a cross-sectional study by $\mathrm{Amoah}^{33}$ on the community prevalence of hypertension in the Greater Accra region. In contrast, other studies from other developing countries have reported high prevalence of hypertension ${ }^{12,14,15,34}$. These prevalence rates could even be higher if effective preventive measures are not instituted ${ }^{35-37}$. There is currently an increasing prevalence of hypertension in developing countries, with rates getting closer and in some settings even higher than the average prevalence reported in developed countries ${ }^{38}$.

Age and gender are underlying risk factors for hypertension and cardiovascular diseases in general and have been an integral part of almost all recent established risk algorithms for cardiovascular diseases. Generally, risk of hypertension is higher in men and increases with increasing age $e^{15,39,40}$ and this was not different from what was observed in this study. However, in contrast with this study outcome, some studies have reported a higher prevalence of hypertension in women ${ }^{41-43}$. The increasing wave of hypertension prevalence in this setting, in contrast to what existed about half a century ago, ${ }^{44}$ could be related to urbanization, lifestyles changes such as increased tobacco consumption ${ }^{45}$, dietary changes and sedentary lifestyles ${ }^{17,46}$. With limited resources for effective treatment and control of hypertension, there is an urgent need to increase the momentum of preventive interventions including efforts to improve awareness and knowledge of hypertension in such areas. Improved level of knowledge and understanding will help early detection of high blood pressure, which is important to avert many damaging conditions ${ }^{47,48}$. A proper assessment and understanding of knowledge and practices (KAP) is therefore essential, especially in the area of chronic conditions such as hy- pertension, for which prevention and control necessitate a lifelong adoption of healthy lifestyles.

\section{Knowledge and Practices related Hypertension}

In this study, awareness of hypertension was high. Some respondents also demonstrated good knowledge of the causes and prevention of hypertension with most of them citing unhealthy diet as the major cause of hypertension in both the qualitative and quantitative studies. Few respondents in this study had high knowledge level on modifiable risk factors of hypertension. This is consistent with previous studies, which reported high awareness of hypertension but low knowledge gaps leading to low level of comprehensive knowledge of hypertension ${ }^{26,29,49}$. Similarly, a study in rural Nigeria ${ }^{28}$ reported a general lack of knowledge about modifiable CVD risk factors. Common risk factors stated in that study included tobacco use, stress, excessive salt intake and lack of exercise. Other studies from the sub-region, ${ }^{28,50}$ also reported low level of comprehensive knowledge of hypertension.

Several misconceptions of the causes of hypertension were exhibited in the qualitative study, with some respondents alluding hypertension to agro-chemicals in farming, eating unhygienic foods, greeting someone with high BP, blood being in excess in the body and drinking cold water from old fridges. This shows that there is the need for increased public health education on hypertension and it causes in this area and other similar settings. These negative perceptions of hypertension would hardly translate to positive health behaviors and therefore the need to demystify them. These misconceptions about the causes of hypertension among study respondents suggest little or no education on hypertension or a possible misinformation.

Access to quality health information improves knowledge on management and control of hypertension ${ }^{51}$. In rural environments, the Community Health Worker (CHW) is the chief source of health information and care. Most respondents in this study cited the media and health worker as main source of health information. Others also cited herbal medicine peddlers as their source of information. There is however a tendency that these herbal sellers have little knowledge of the epidemiology of disease conditions and most often might thwart information to promote their medicines. An effective health promotion intervention in this setting is therefore suggested. 


\section{Educational level and Knowledge of hypertension}

This study found an association between educational level and knowledge of hypertension. Although educational attainment has been improving over the years in Ghana, a chunk of rural folks still remain uneducated, compared to those in urban settings ${ }^{52}$. Awareness of hypertension was significantly higher among the educated. This is consistent with findings from previous studies, ${ }^{29,53,54}$ all of which reported a positive correlation between education and knowledge level of hypertension. This could be partly due to differences in mass media exposure in Ghana, which has been shown to be low among the uneducated ${ }^{52}$. This has been attributed to less ownership of radio and television sets among the uneducated (most likely to be poor). This section of the population is also less likely to utilize health services. Educational interventions should be well structured to improve uptake among both the educated and uneducated.

\section{Limitations of the study}

This study might have suffered some response biases, as it was difficult validating responses. It was however presumed that participants were honest and gave answers that were a true reflection of what was happening in the study communities. Again, questionnaires and interview guide were administered in the local language and some terms could not be translated appropriately, which may have misled the findings. It is believed that the use of mixed methods; qualitative and quantitative could have validated findings through triangulation and thus making these findings reliable.

\section{Conclusion}

This study has unveiled important barriers to hypertension prevention; lack of appropriate information about hypertension and misconceptions. The study further identified a positive enabler; high level of awareness which is useful in realigning existing interventions to prevent and control hypertension in rural settings.

\section{Ethical consideration}

The Committee on Human Research Publications and Ethics (CHRPE) of Kwame Nkrumah University of Science and Technology (KNUST) granted ethical approval for this study. Permission was again sought from the Dis- trict Health Directorate. The intent and procedures of the study were explained to participants, who gave written consent before enrolment in the study.

\section{Competing interests}

Authors declare that there are no competing interests.

\section{Authors' contributions}

PAB and GT designed the study. GT collected the data and was analysed by DB. DB and DYQ wrote the first draft of the manuscript. All authors reviewed and accepted the final manuscript for publication.

\section{Acknowledgement}

We express our gratitude to the District Director of Health Services (Asutifi South, Ghana) Mrs. Catherine Andoh, the Management of St. Elizabeth Catholic Hospital and all the respondents involved in the study for their time and participation.

\section{References}

1. World Health Organization. Reducing risk, promoting healthy life. Geneva, Switzerland: World Health Report 2002.

2. Joint National Committee (JNC) on Prevention, Detection, Evaluation and Treatment of High Blood Pressure: The JNC 7th Report. JAMA 2003; 289: 2560-2572. 3. Kearney PM, Whelton M, Reynolds K, Whelton PK, He J. Worldwide prevalence of hypertension: a systematic review. J Hypertens. 2004; 22:11-19.

4. Bhatt DL, Steg PG, Ohman EM. International prevalence, recognition and treatment of cardiovascular risk factors in outpatients with atherothrombosis. JAMA. 2006; 295: 180-189.

5. Gunaranthne A, Patel JV, Potluri R, Gill PS, Hughes EA, Lip GYH. Secular trends in the cardiovascular risk profile and mortality of stroke admissions in an innercity, multiethnic population in the United Kingdom 19972005. J. Hum. Hypertens. 2008; 22: 18-23.

6. American Heart: Heart Disease and Stroke Statistics-2010 Update: A Report from the American Heart Association. Dallas, Texas. American Heart Association. 2010; 46-215.

7. World Health Organization. World health statistics. Geneva. World Health Organization. 2009. 
8. World Health Organization. Global status reports on non-communicable diseases. Geneva, Switzerland. 2014. 9. O'Flaherty M, Buchan I, Capewell S. Contributions of treatment and lifestyle to declining CVD mortality: why have CVD mortality rates declined so much since the 1960s. Heart. 2013; 99:159-62.

10. Ministry of Health. The Ghana Health Sector Programme of Work 2006. Ghana, 2007.

11. Bosu W. Epidemic of hypertension in Ghana: a systematic review. BMC Public Health. 2010; 10:418

12. Addo J, Amoah AGB, Koram KA.The changing patterns of hypertension in Ghana: a study of four rural communities in the Ga district. Ethn Dis. 2006; 16:894 899.

13. Agyemang C, Bruijnzeels MA, Owusu-Dabo E. Factors associated with hypertension awareness, treatment, and control in Ghana, West Africa. J Hum Hypertens. 2006; 20:67-71.

14. Burket BA. Blood pressure survey in two communities in the Volta region, Ghana, West Africa. Ethn Dis. 2006 16:292-294.

15. Cappuccio FP, Micah FB, Emmett L, Kerry SM, Antwi S, Martin-Peprah R, Phillips RO, Plange-Rhule J, Eastwood JB. Prevalence, detection, management, and control of hypertension in Ashanti, West Africa. Hypertens. 2004; 43:1017-1022.

16. Asutifi South District. Annual Report 2012. Kenyasi, 2013.

17. Opie LH, Seedat YK. Hypertension in sub-Saharan African populations. Circulation. 2005; 112: 3562-68

18. Jolles EPA, Clark AM, and Braam B. Getting the message across: opportunities and obstacles in effective communication in hypertension care. Journal of Hypertension. 2012; 30: 1500- 1510.

19. Okoro RN, Ngong CK. Assessment of patient's antihypertensive medication adherence level in non-comorbid hypertension in a tertiary hospital in Nigeria. Int $J$ Pharm Biomed Sci. 2012; 3: 47.

20. Rosenstock IM, Strecher VJ, Becker MH. Social learning theory and the health belief model. Health Educ Q. 1988; 15:175-183.

21. Farquhar JW, Maccoby N, Wood PD. Education and communication studies In: Holland WW, Detels R, Knox G, eds. Oxford Textbook of Public Health.Oxford, UK. Oxford University Press. 1985, 207-221.

22. Prochaska JO, DiClemente CC, Norcross JC. In search of how people change: application to addictive behaviours. Am Psychol. 1992; 47:1102-1114.

23. Busari OA, Olanrewaju TO, Desalu OO, Opadijo OG, Jimoh AK, Agboola SM, Busari OE, Olalekan O. Impact of Patients' Knowledge, Attitude and Practices on Hypertension on Compliance with Antihypertensive Drugs in a Resource-poor Setting. TAF Prev Med Bull. 2010; 9(2):87-92.

24. Borzecki A. The effect of age on hypertension control and management. Am J Hypertens. 2006; 19: 520-527. 25. Ard JD, Svetkey LP. Diet and blood pressure: applying the evidence to clinical practice. Am Heart J. 2005; 149: 804-812.

26. Rizwana BS, Elsheba M, Jayadevan S, Jayakumary M, Shatha AS, Shaikh AB. Knowledge regarding risk factors of hypertension among entry year students of a medical university. J Family Community Med. 2011; 18(3): 124-129. doi: 10.4103/2230-8229.90011

27. Iyalomhe GBS, Iyalomhe SI. Hypertension-related knowledge, attitudes and life-style practices among hypertensive patients in a sub-urban Nigerian community. $J$ Public Health Epidemiol. 2010; 2, 71-77.

28. Oladapo OO, Salako L, Sadiq L, Soyinka K, Falase AO. Knowledge of Hypertension and other Risk Factors for Heart Disease among Yoruba Rural SouthWestern Nigerian Population. British Journal of Medicine \& Medical Research. 2013; 3(4), 993-1003.

29. Aung MN, Lorga T, Srikrajang J, Promtingkran N, Kreuangchai S, Tonpanya W, Vivarakanon P, Jaiin P, Praipaksin N, Payaprom A. Assessing awareness and knowledge on hypertension in an at-risk population in the Karen ethnic rural community, Thasongyan, Thailand. International Journal of General Medicine. 2012; 5: 553-561.

30. Ghana Statistical Service (GSS). Population and housing census 2010. Ghana statistical service, Accra, Ghana, 2013.

31. NVivo qualitative data analysis Software. Version 10. QSR International Pty Ltd, 2012.

32. StataCorp. Stata Statistical Software: Release 11. College Station, TX: StataCorp LP, 2009.

33. Amoah AG. Hypertension in Ghana: a cross-sectional community prevalence study in greater Accra. Ethn Dis. 2003; 13(3):310-5.

34. Kunutsor S, Powles J. Descriptive Epidemiology of Blood Pressure in a rural adult population in Northern Ghana. Rural Remote Health. 2009, 9:1095. 
35. Khor GL. Cardiovascular Epidemiology in the Asia Pacific Region. Asia Pac J Clin Nutr. 2001; 10:76-80.

36. Vorster HH. The emergence of cardiovascular disease during urbanisation of Africans. Public Health Nutr. 2002; 5:239-243.

37. Addo J, Smeeth L, Leon DA. Hypertension in sub-saharan Africa: a systematic review. Hypertension. 2007; 50:1012-1018.

38. Ostchega Y, Yoon S, Hughes J, Louis T. Hypertension Awareness, Treatment, and Control-Continued Disparities in Adults. United States, 2005-2006. PubMed. National Center for Health Statistics, 2008.

39. Agyemang C, Redekop WK, Owusu-Dabo E, Bruijnzeels MA. Blood pressure patterns in rural, semi-urban and urban children in the Ashanti region of Ghana, West Africa. BMC Public Health. 2005; 5:114.

40. Agyemang C. Rural and urban differences in blood pressure and hypertension in Ghana, West Africa. Public Health. 2006; 120, 525-533.

41. Smith WC, Lee AJ, Crombie IK, Tunstall-Pedoe H. Control of blood pressure in Scotland: the rule of halves. BMJ. 1990; 300:981-3.

42. Whelton PK. Epidemiology of hypertension. Lancet. 1994; 344:101-6. 33.

43. Cappuccio FP, Plange-Rhule J, Phillips RO, Eastwood JB. Prevention of hypertension and stroke in Africa. Lancet. 2000; 356:677-8.

44. Shaper AG, Wright DH, Kyobe J. Blood pressure and body build in three nomadic tribes of northern Kenya. East Afr Med J. 1969; 46:273-81.

45. Kerry SM, Emmett L, Micah FB, Martin-Peprah R, Antwi S, Phillips RO, et al. Rural and semi-urban differences in salt intake, and its dietary sources, in Ashanti, West Africa. Ethn Dis. 2005; 15:33-9.

46. Yusuf S, Reddy S, Ounpuu S, Anand S. Global burden of cardiovascular diseases: part I: general considerations, the epidemiologic transition, risk factors, and impact of urbanization. Circulation. 2001; 104:2746-53.

47. Kusuma YS, Gupta SK, Pandav CS. Knowledge and Perceptions about Hypertension among neo- and settled -migrants in Delhi, India. CVD Prev Control. 2009; 4:11929.

48. Familoni BO, Ogun SA, Aina AO. Knowledge and awareness of hypertension among patients with systemic hypertension. J Natl Med Assoc. 2004; 96:620-624.

49. Addo J, Agyemang C, Smeeth, L A, De-Graft A, Edusei AK, Ogedegbee, O. Review of population-based studies on hypertension in Ghana. Ghana Medical Journal. 2012; 46 (2):4-11.

50. Miller H, Berra K, Long J. Awareness, understanding, and treatment of previously diagnosed hypertension in baby boomers and seniors: a survey conducted by Harris interactive on behalf of the preventive cardiovascular Nurses association. The Journal of Clinical Hypertension. 2009; 12 (5), 328-334.

51. Beigi MAB, Mohammad J Z, Kamran A, Abutaleb J, Shahnaz S, and Hajar K. The Effect of Educational Programs on Hypertension Management. Int Cardiovasc Res J 2014; 8(3): 94-98. Published online 2014 Sep1.PMCID: PMC4109043

52. Ghana Statistical Service (GSS), Ghana Health Service (GHS), and ICF International. Ghana Demographic and Health Survey 2014. Rockville, Maryland, USA: GSS, GHS, and ICF International, 2015.

53. Mehrotra R, Bajaj S, Kumar D, Singh KJ. Influence of education and occupation on knowledge about diabetes control. Natl Med J India. 2000; 13(6):293-6.

54. Samal D, Greisenegger S, Auff E, Lang W, Lalouschek W.The Relation between Knowledge about Hypertension and Education in Hospitalized Patients with Stroke in Vienna. Stroke. 2007; 38:1304-1308 